\title{
The Meaning of the Moves: Gestural Mythologies and the Generic Film
}

Sarah Friedland, Independent Artist

\begin{abstract}
This essay investigates the role of gestures in the production of film genre. These repeated moves-generic gestures-operate in and signify mythologies that produce film genre. This paper seeks to animate theories of the gesture while theorizing film genre as a choreography that is performed across film texts and bodies. It moves the notion of the genre "corpus" towards a mobile concept that privileges the gestural exchanges occurring between bodies of actors, of viewers, and of films.
\end{abstract}

Keywords: gesture, film genre, mythology

i. Cowboys sink into their hips, pushing against their gun holsters. Their hands know when to reach for the gun and shoot.

ii. The last girl spirals around herself, curling her spine. Her back feels the incipience of danger and possible death (killer) behind her.

iii. The girl-falling-in-love's chin cuts transversally through the space around her. Her chin knows what love looks like.

\section{Introduction}

We need to pay more attention to the meaning of the moves in the movies. We need to look at the specificity of gestures: at how the cowboy extends his fingers towards his gun; how the last girl spirals her torso to glimpse her would-be killer; how the girlfalling-in-love tilts her head up to see her lover. These moves-cinematic gesturesoperate in and signify mythologies that are as crucial to film genre's semiosis and production as visual iconography or seminal actors. Gestures are sites-or events-of the generic and its production. Further, the kinesthetic impact of these gestures in the bodies of film spectators - their residues, affects, and memory-are both effects and co-producers of the generic. 
This paper responds, in part, to the lack of attention from academic scholarship to the particularity of the movement of filmic bodies. These moves construct meanings, knowledges, affects, genres, and more, and yet they have been undertheorized in film studies. It is crucial for scholars to approach the study of cinema with a detailed attention to the moves of onscreen bodies. As Erin Brannigan has noted:

while dance studies has often kept its distance from debates in film theory, film has also avoided dialogue with issues in dance studies ... Dance theory offers understandings of the moving body and its ability to produce and express meanings that are particularly useful for addressing both popular film genres and other categories of dancefilm. ${ }^{1}$

This essay takes up a methodology in between film studies, semiotics, and dance and performance studies so as to arrive at a theory of genre production and gesture that privileges neither the moving body nor the moving image but instead explores the unique conditions created through their coproduction and constitution. ${ }^{2}$ In his 2004 book on gesture, Adam Kendon notes that there has been a "revival of gesture studies." ${ }^{3}$ Yet, to my knowledge, that revival has not fully permeated film studies. The gesture is taken up in social psychology, linguistics, and performance studies, largely in terms of non-verbal communication and performance, but it has not been taken up as a distinctly cinematic construction. It is as such that I would like to treat the gesture, recuperating it from a static treatment in which it is assimilated to iconography, poses or linguistic units. Rather than theorize all gestures, this paper addresses a physical gestural modality within Hollywood cinema. It is designed to produce neither a totalizing theorization, nor a historical genealogy, nor even a classification scheme for generic gestures, but rather to isolate filmic gestures that elucidate how film genre is itself choreographic. By treating genre as a choreography, and attending to the specificity of generic gestures, I hope to model the way in which dance studies can fruitfully be brought into theories of film. This project also suggests the multiple ways in which gesture is productive for theorizing film genre while animating the classifications and theorizations of gesture in both theories of film and performance as well as popular notions of gestures. Cinema's construction of genre has mediated understandings and enactments of gesture that go beyond film itself.

By looking to gesture, we move film genre theory away from a static and typological model and towards a mobile concept of genre that attends simultaneously to repetition and difference while rethinking the notion of a corpus, ${ }^{4}$ or body, of generic film texts. As a basic definition of genre films, Barry Grant suggests that "genre movies are composed of certain common elements." ${ }^{5}$ He underscores the role of repetition, stating genre films "tell familiar stories with familiar characters in familiar situations." ${ }^{6}$ In genre theory, the repetition of elements has historically been used as a classification scheme in which the appearance of a certain element signals a corresponding genre. For example the presence of horses or cowboys signals that a film is a Western. In his 
work on genre, Rick Altman suggests that genre exists in a multiplicity of locations. ${ }^{7}$ And yet both genre theory and popular conceptions of genre privilege certain sites. Examples of these sites include the actors who repeatedly appear across films, visual iconography, narrative tropes and plot similarities, to name a few. Attempts in genre theory to read these elements intertextually and to position viewers and their expectations as co-producing and participating in genrefication destabilize the aforementioned theories of genre that are static and formulaic in their classification schemes. For example, Barry Keith Grant's writing on genre underscores the role of viewers, stating how "conventions function as an implied agreement between makers and consumers to accept certain artificialities. ${ }^{8}$ Contemporary genre theorists tend to agree "genres are neither static nor fixed." ${ }^{\text {9 }}$ Yet they have failed to provide an adequate lens or site through which to trace the animate and mobile process by which film genre and the generic is continuously produced. Gestures offer a literally moving site. As Altman notes:

A fundamental problem of genre studies stems from the ever-present desire for a stable and easily identifiable object of analysis. Ever simplifying, genre critics have simply borrowed an ontology, a methodology and an epistemology developed by critics of art and literature for other objects and other purposes, thereby reducing the notion of genre to a corpus of texts or to textual structure. We do better, I suggest, to treat genre as a complex situation, a concatenated series of events regularly repeated according to a recognizable pattern. ${ }^{10}$

The gesture as a mobile site for the study of genre is comparable to the event or situation that Altman craves for his particular analytic. Generic gestures follow a pattern; they repeat, but with difference, in every filmic iteration or performance. Their difference is produced by the particularity of the body performing the gesture, the diegesis in which it is performed, the framing and cinematography that captures it, and the editing which mediates-dis- and re-assembles-it. Considering Derrida's writing of genre as a "corpus of traces,"11 we might think to follow the gesture as a generic trace across film texts and viewing bodies. Tracing the generic via physical gestures enables a more animated and dynamic consideration of film genre.

Gestures can be conceptualized not only as a repetitive tendency of genre films, but as the choreography of film genre itself. They are the unfolding of a generic code inscribed in and through moving bodies, both on and off screen. Particular gestures are repeated and recapitulated, without uniformity, across films. These gestures come to hold conventionalized meanings and functions within genre films. By looking to read genre in the gestures of films, genre becomes not a formula that includes certain iconographic and narrative clichés, but a choreography in which movements are repeated but performed differently in each iteration. For example, while we might conceptualize the choreography of slasher films as including the gesture of a scream, 
in which the last girl's eyes and mouth widen to their most extreme limit, this very gesture will be performed with countless variations in its movement quality as it is performed across film texts and bodies. As Steve Neale has theorized, "genres are instances of repetition and difference." ${ }^{12}$ Bringing in notions of the choreographic and theories of performance to the study of genre film accounts simultaneously for the recurrence of the familiar and the simultaneous presence of difference. The bodies participating in genrefication are threefold: first, they are the bodies of the filmic actors, and, secondly, they are the bodies of viewers. But further, in the exchange between these two bodies, through the gestures that they mutually recognize, share, and endow as significant and signifying, there is produced a third corpus of genre: a body of choreography.

These generic gestures signify as what Roland Barthes designated "myths" - "a second-order semiological system." ${ }^{13}$ With myths, "that which is a sign (namely the associative total of concept and an image) in the first system, becomes a mere signifier in the second"14 such that "the meaning is already complete, it postulates a kind of knowledge, a past, a memory, a comparative order of facts, ideas, decisions." ${ }^{15}$ In the case of generic film gestures, the movements performed do not signify what Barthes calls a "first-order" signified, but rather, an already complete order of knowledge. For example, a young woman kissing a man at the end of a chick flick does not merely signify her love and desire for the particular man in the film, but rather the mythology that for heterosexual women there is "the one" that is somewhere "out there" who will guarantee happiness and fulfillment upon romantic and sexual union. Filmic gestures thus function to inscribe the generic and its mythological meanings through corporeal movement. Film genre theorist Barry Keith Grant also underscores the links between Barthes' notion of "myth" and genre film, writing, "entertainment inevitably contains, reflects and promulgates ideology. It is in this sense of entertainment as ideology that Roland Barthes uses the term myth." ${ }^{16}$ Further, he asserts that Barthes' "description of cultural myth applies perfectly to genre movies: 'myth does not deny things, on the contrary, its function is to talk about them; simplify, it purifies them, it makes them innocent, it gives them a clarity which is not that of an explanation but that of a statement of fact."'17 Generic film gestures possess this excessive clarity; the performance of an individual gesture by a film actor signifies a generic statement of fact. It is this clarity that allows them to circulate, contagiously, between bodies and films, actively participating and catalyzing the process of genrefication. The semiotic and mythological labor of genre films is performed by onscreen bodies and reenacted repetitively by viewing bodies who take up these exchanged gestures, extending genrefication outside the diegesis. 


\section{Animating Theories of the Gesture}

"Gesture" faces a problem of definition. The word is deployed to refer to a variety of phenomena and objects. Its polysemous quality is symptomatic of the way gestures operate. Unlike the specificity and relatively fixed nature of linguistic signifiers and their signifieds, most gestures do not have singular referents or signifieds but rather move or reach towards meanings, and more so, mythologies. Indeed, the current trend in academia of using the word "gesture" to indicate a mode of speculation or a pointing towards a particular area of interest reflects the way in which the gesture (as a physical motion and sign) does not reach a point, but rather moves towards the possibility of one. In these academic utterances, "gesture" is used so as to suggest not a clear act of signification but rather one that approaches signification, moves towards meaning. This current usage suggests a process of constantly approximatingnearing-something. The very moving quality of gestural signification is further reflected in the physical act of gesturing itself in which the body is not static but actively moving towards as a way of producing meaning. In a broad sense, this is how I define and use gesture in this paper: gesturing is meaning through movement, involving a process of animatedly approaching signification.

We need to animate theories of the gesture. Historically, gestures have been studied typologically, placed in paneled diagrams in which each gesture gets a singular static image in a particular pose or position. For example, hand gestures are often represented in still and singular images, the frame cutting the hand off at the wrist, in various positions. Such diagrams are indicative of a popular conception of gesture, a static image or object that is echoed also in certain academic treatments. While static treatments of gesture may appear to be clarifying, such a view actually effaces the ways that, as precisely moving signs that are always in process and production, gestures animatedly produce meaning. In the example of represented hand gestures, the hand becomes an object, a singular entity, and in its pose considered (erroneously, I argue) to be a "gesture." Indeed, the gesture is often mistaken for micro-poses. As such, gesture becomes delimited as a particular configuration of a body part, unrecognized as an act of moving. This static representation threatens to assimilate analysis of movement to the pose and of meaning to a simply linguistic deconstruction. Such assimilation fails to account for the mobile and multiple ways in which gestures signify. Dance and screendance studies, in their attention to the continuity of the body and its meanings, can help to animate theories of the gesture outside of so-called dance texts.

The project of animating semiotics and addressing the continuous within formal structures, while incorporating the interventions of poststructuralism, is one articulated by Brian Massumi, who writes: 
Theoretically, the point of departure would have to be to part company with the linguistic model at the basis of the most widespread concepts of coding (almost always Saussurian in inspiration, often with Lacanian inflections) and find a semiotics willing to engage with continuity. ${ }^{18}$

For Massumi "continuity" is a condition of bodies being mobile as opposed to attending to fixed positions on a grid, a positioning he designates as homologous to the code. While Roland Barthes' writings on myth are based in the Saussurian model that Massumi and poststructuralists try to depart from, the particularity with which he treats the link between the mechanics and texture of movement and the mythological meanings they signify is a salient example of how a semiotic treatment of movement can account for meaning that is continuous. That is, Barthes does not fully achieve the mobile semiotics that Massumi desires, but he gestures towards it. In Mythologies, Barthes analyzes how the body/physique and movements of a wrestler produce spectacles that signify strength and weakness, and triumph and defeat, operating within the larger mythologies of the world of wrestling:

It is at every turn during the fight, in each new situation, that the body of the wrestler casts to the public the magical entertainment of a temperament which finds its natural expression in a gesture...the wrestler arranges comments which are episodic but always opportune, and constantly help the reading of the fight by means of gestures, attitudes and mimicry which make the intention utterly obvious. ${ }^{19}$

Barthes underscores the signifying potential of gesture as well as its mythological function. Nonetheless, Barthes does not fully allow for movement itself to be the significant signifying form. Barthes focuses on the physique of the wrestler, objectifying him and relegating his movement to a performance that is secondary to the body as object (muscle) and image. Yet Barthes further suggests the signifying potential of gesture in his attention to the specificity of the wrestler's moves:

The forearm smash, this loud slap of the forearm, this embryonic punch with which one clouts the chest of one's adversary, and which is accompanied by a dull noise and the exaggerated sagging of a vanquished body. In the forearm smash, catastrophe is brought to the point of maximum obviousness. ${ }^{20}$

In his description of the forearm smash Barthes refers primarily to the noises made by the moves of the wrestler, rather than attending directly to the details of the moves themselves. Yet each onomatopoeic noise he references suggests a particular gesture: smash, slap, punch. His invocation of sound signifies a rich level of textural detail; the sounds appear as evidence of movement quality. As such, Barthes presents mythologies that are formed through movement and its textures and qualities. 
Herein, I will attempt to engage with a semiotics that attends to mobility, as requested by Massumi, and yet achieves the level of detailed engagement with mythological meaning through movement, as demonstrated by Barthes. The gestures, however, will be limited to a cinematic realm, exchanged between film texts and spectators' bodies.

\section{Cinematic Gesture/Genre}

The movement qualities of gestures performed in genre films signify generic mythologies and participate alongside the repetition of other elements in genre production. The static treatment that I previously suggested has dominated the study of gesture is also present in the study of genre films: the complexity of physical movement is neglected or assimilated to the iconography present within the mise-enscène. This assimilation is exemplified by the treatment of the gesture of smoking in noir films. While all the other elements of the mise-en-scène are acknowledged as marking and producing the noir-ness of a film - the contrast of the lighting against the cigarette smoke, the physiognomy of the femme fatale's face, the repetition of certain star actors associated with the genre, etcetera-the actual quality of the face and body that perform the gesture go largely unacknowledged. The slow pace of the femme fatale's lips parting for the cigarette, the way in which her head slowly bows towards the open flame of a man's lighter, the wide and circular opening of the mouth that blows smoke-none of these kinesthetic qualifications of the gesture are given the attention and detail required to mark genre as something corporeal. It is in light of this deficiency that dance studies, and more so screendance studies, can help produce a more nuanced account of filmic movement and its role in genrefication. The specificity of gestural movements performed in film texts-what Brannigan has called the "idiogest"21_produces and constitutes the generic itself. The assimilation or subjugation of gesture to genre's iconography, reduces the meaning of the moves, which yield the generic substance of a film.

More than the mere presence of gestures within genre films, the exchange of these gestures between on-screen and off-screen bodies participates in genre production. This relation between bodies is what Brannigan calls gestural exchange, which she formulates by distinguishing Lyotard's notion of gesture from other definitions:

Lyotard uses the terms gesture and gestus to describe the various elements of aesthetic production and reception which together constitute a model of gestural exchange, from the work of the artist, to the components of the work of art, to the immediate response of the viewer and the labor of the philosopher's discourse. These ideas suggest a gestural contagion and fluidity between performers, between performers and spectators, between films, and between disciplinary boundaries. ${ }^{22}$ 
Brannigan's notion of "gestural exchange" reconfigures the genre film corpus as not merely a collection of texts, but a body of gestural transferences between films and viewers and their discourses. To be clear, while Brannigan and Lyotard's notions of gesture extend beyond physical movements performed by humans, the gestures that I invoke here are solely physical and human.

By addressing genre as a gestural exchange, we are better able to account for its hybridity. Derrida asks in "The Law of Genre," "what if there were lodged within the heart of the law itself, a law of impurity or a principle of contamination?"23 His question, and the larger essay of which it is a part, suggest the way in which texts cannot be sealed off and contained to the marks of one genre, but rather, must participate in many. "Contamination," as a law of genre, suggests the contagious spread of generic elements across texts. Gestural exchange occurs not just between acting and viewing bodies and intertextually across the films of a genre, but between the choreographic corpuses of different genres. For example, the gestures of the cowboy's hands, about to shoot a gun in a Western, are not contained to their Western diegesis. They contaminate and permeate the gun-shooting gestures of action heroes, about to pull the trigger on villains. The gun-shooting of the cowboy is not sealed off from the gun-shooting of other genre's archetypal figures and the choreography they perform. We might trace familiar gestures across genres as a way of addressing gestural exchange as the very means of genrefication. The body itself is a site of contamination; it exchanges and mixes its filmic and mythological moves.

Generic gestures operate with, and are produced by, other filmic elements such as lighting and cinematographic framing. In particular, the close-up produces generic gestures. Of course, gestures occur in genre films that are not framed in close-up, but rather in wide shots. In these cases, however, the gestures are already legible without the particular cinematographic framing. That is, knowledge or discourses about the part of the body (or whole body) gesturing, allow the movement to be discernible as a gesture without the mediation of the frame. For example, a hand can wave goodbye in a wide shot in a film without the need for a close-up to isolate the hand as gesturing. For the human movement or micromovement that is performed by a part of the body that is not easily metonymic like the hand, the frame of the close-up engenders an autonomy that produces the status of "gesture." This process is clarified by Brannigan's theorization of "cinechoreography," which was developed in relation to dance film but can be usefully extended to consider filmic movement more broadly. Drawing on Bela Balacz's theorization of the close-up and faceity, Brannigan underscores the role of the close-up in producing gesture:

The close-up in dancefilm creates a specific cine-choreographic order by extending and redefining the parameters and nature of screen performance and thereby extending the parameters of dance. This is achieved through an attention to the performing body and its micro- 
movements - the smaller detailed movements of the body and its parts. This can often produce a deterritorialization of the body so that any part of the corporeal whole can operate as a site for dance and, thus, meaning production and expression. ${ }^{24}$

By framing in close-up the micro-movements of the body, the work of cinematography creates gestures; that is, the frame produces the gesturing potential of non-territorialized parts of the body. With the segmenting and focusing work of the cinematographic frame, any part of the body can attain the isolation and metonymy that the hand is seen as already possessing. The close-up endows the whole body as inherently (and through segmentation, necessarily) gestural; the metonymic function of gesture is amplified by the segmentation of the cinematic frame. Thus, gesture as such, is a cinematic construction.

\section{Three Gestural Mythologies: Horror, Chick Flick, Western}

The filmic gestures I invoke here encode myths as a part of the narrative and ideological work of genre films. To illustrate this argument, I offer three examples of such gestural, and generic, mythologies. The gestures described below are not emblems or essences of their genres. Rather they are salient examples of how attending to gestural particularity can yield a richer film studies that is better able to account for the production and operation of cultural mythologies. Given this tie to mythology, I borrow, with a difference, Barthes' style of glossing-in brief excerptsmyths from Mythologies. His glosses simultaneously account for the depth of layers and levels of signification that compose myth, while allowing for the at once of the myth:

Myth essentially aims at causing an immediate impression-it does not matter if one is later allowed to see through the myth, its action is assumed to be stronger than the rational explanations which may later belie it. This means that the reading of a myth is exhausted at one stroke. ${ }^{25}$

While gestures offer a semiotic work that is likewise both immediate and affecting, their signified is irreducible. The "difference" that I add to Barthes' method is of focus: a detailed account of the movement of the body.

I have deliberately chosen to address these generic gestures in a descriptive mode that abstracts them from actual films, rather than reading closely particular iterations of gesture within singular film texts. Were I to write of particular gestural iterations, I would be highlighting certain gestures as exemplary of the genre, rather than reading them as particular and unique performances of a generic choreography that is produced across numerous film texts and bodies. In its detailed attention to an abstracted choreography, my mode of address recognizes genre as being iterated and 
produced intertextually. In the inability to study genre in a singular text, Altman iterates the problematic of genre:

Students of genre forever forego such security [offered by a stable object of study]. Genre offers neither a unique object of study nor the stability of an exactly duplicated text. There exists no generic original of which particular events might be represented as performances. Present in no specific place at any particular time, the notion of genre cannot be adequately grasped through the models offered by art, literature, theatre or film. The oldest cliché in genre studies holds that a single text cannot constitute a genre. Less obvious, but no less important, stands the fact that genres are never made up of texts alone, however numerous. Because the very notion of genre depends on the existence of audience activity (prior knowledge of similar texts, intertexual comparisons, specific cognitive tendencies and predictable schema-processing practices), no genre critic can afford to treat so-called generic texts in a vacuum. ${ }^{26}$

The descriptions of movement that follow do not stand as writing of gestures that are "exactly duplicated" in every film of its genre-no such exactly replicable gesture exists. Yet certain characteristics of movements can be read across these different iterations. For example, cowboys might collapse from being shot in the gut in endlessly different ways across film texts, and yet, the majority of these gestures will include a quick and sharp contraction in the abdomen. It is this strain of kinesthetic repetition and familiarity that these descriptive passages attempt to address.

Additionally, this form of address attempts to conjure a collective imagination of the gestural choreography of the genres addressed herein. Film genre theorist Andrew Tudor writes of the role of the imagined in film genre:

to talk about the western is (arbitrary definitions apart) to appeal to a common set of meanings in our culture. From a very early age most of us have built up a picture of the western. We feel that we know a western when we see one, though the edges may be rather blurred ... Genre is what we collectively believe it to be. ${ }^{27}$

By describing these choreographies as abstracted from individual films, I am attempting to address this collective imagination of genre not as a visual and aural knowledge, but as a kinesthetic one. That is, to attempt to conjure the Western not just by the image of a six-shooter and the sound of its deployed bullets, but by the contracting abdomens which violently receive them. The gestures described herein suggest the way in which genre is a choreography that our bodies collectively recognize, participate in, remember, and critique. 
1. Slasher/Horror Film: The slowly spiraling head and upper torso-the look back-of the last girl

As the "last girl" is being chased, she looks back. Her spine knows that she is in danger. So too do the hairs on the back of her neck. She is hunched over as she runs, her spine curved and her abdomen contracted, in anticipation of something-bad-that-has-not-yethappened. Her shoulders rotate inwards, retracting from the danger that lurks behind their sockets. She spirals - turning her torso-as if lightly wringing a rag, from the abdomen to the neck. Something is behind her-risk is always behind the back of the last girl, rarely in front. She feels danger in her back; her spine wants to know who is following her. Her skin wants to know if it will be torn. The spiral is her way to find out, to turn on herself to know her fate, which is directly behind her back, out of sight. Her back feels the risk; her spine must suss it out. The body slowly curves around itself, its spine an axis, reaching finally to the head. Once the head is fully turned, she will know what is behind her. The eyes are the final point of the spiraling gesture. The spiral says she is chased. The spiral says she in danger. The spiral says if she will live or die. The spiral says there is an other who is not her friend or lover. The spiral is her horror, waiting to happen upon the reveal of what or who is behind.

\section{Chick Flick: The timid chin of the girl falling in love}

Her chin is timid. It moves, not with force but with a question. The eyes-which want to see him-must get the chin's permission first. Sometimes he passes her in the hallway at school. As if a cue syncing the musculature of her face with his locomotion, she gets tied to him, gliding her features horizontally to see his passage past lockers and others she does not know. She moves to look. He has passed. The rounded tops of her shoulders know he is still behind her, moving further away She must make a move, fast: her chin cuts transversally through the air, reaching her shoulder blade-it stops-he is behind but not looking. She retraces, her chin sinking, the space between her shoulder and her upper chest. He is not looking back-her chin must therefore return. Her chin looks for love-it stops when love looks back at her face. In the moves of the chin, and the face it drags with it, we see her falling-in-love, with him. Like the last girl whose back determines the danger behind her, this girl's chin thinks, possibly, that it's falling in love. Her chin is suspecting; it suspects that its lateral motion that infects the spiraling spine and turning head moves towards the one she will love. In the turning chin, and what it brings, we see her falling in love. The chin falls first, her gaze follows, and with it we know where her heart is. Thus, her chin gestures in place of her heart's unseen moves.

3. Western: The ready hands of the cowboy, about to shoot

The hands of a cowboy know. Held just beside his legs, they take stock of the air around them. In the vibrations of the air and the sand particles in it, they will know. They keep their shoulders broad, ball securely in socket, pulling down the back. Their backs and torsos locked like their guns. From that locked and ready base, the hands get to hang, not passive 
but waiting, anticipating, ready. In the suspended hands of the gunslinger, we see his keen sense, his superiority, his all-knowing ability to work a saloon room, work a gunfight, work on anything, all to his benefit and success. He trusts no one, or very few, but he does trust his hands, for they know. One hand slips down towards his gun holster. In this steady slip, the other, and we, know he is ready, he is serious, he will shoot. But he doesn't-his hands will know when it's the right time. His hands read the diegetic space, and we read and trust them. His hips may shift, his weight need not be static, pushing against his gun holster, but his hands are unerring in their attention, in their focus. His eyes squint, but the hands do the real looking. His hands see the hands of the other and know when to react. Here is a gestural exchange in the diegesis: mano a mano.

The viewer apprehends mythological and ideological meanings from their kinesthetic reception of these gestures. In the spiraling spine of the last girl, we read the constant possibility of horror and violence inflicted against women; in the transversal chin and eyes of the chick flick's leading lady we read the promise of happiness and fulfillment in heterosexual romance; in the steady hands of the cowboy, we read the confident and arrogant enterprise of white men on a new frontier. Reading the mythological meaning of genre films is accomplished by reading its gestures. This "reading" however, is not simply specular, but rather embodied, affected and empathetic. Apprehension of gesture, and thus apprehension of genre, is a kinesthetic practice enacted by the spectator.

\section{Embodied Spectatorship and Affects of the Generic Gesture}

The body is both the persistent site of self-recognition and the thing that always betrays us.

—Kathleen Stewart, Ordinary Affects, 114.

In its affects, kinesthetic recognition, critique and empathy with filmic gestures, the spectator's body co-produces genre. Framing the kinesthetic response and affects of film viewers not as effects of film but rather as participants in the choreographic performance and production of genre, reconsiders genrefication as an affective, and kinesthetic exchange. It suggests that genre production is enacted, and made possible, by the body's status as moving and move-able, affected and affecting. The repetition of these generic gestures across films enables their easy recognition by the spectator. Indeed, while film theorists have emphasized the discernibility of visual iconography, these gestures, while apprehended by the vision of the viewer, are recognized even more fully by the body of the viewer.

As theorists like Linda Williams and Vivian Sobchack have emphasized, the viewer must be acknowledged as embodied and somatically agentive. ${ }^{28}$ This viewer thus literally feels the moves of a film and makes sense of the film through her body and senses. As Vivian Sobchack precisely articulates in her formulation of the "cinesthetic 
subject" for whom cinema is "somatically intelligible," "the film experience is meaningful not to the side of my body, but because of my body." ${ }^{29}$ These embodied accounts of spectatorship that do not neglect the body's sensorium as a site of knowledge make way for an understanding of the role of the spectator's body in genre production. Brannigan notes how attention to such theories of embodiment have produced a greater consideration of the kinesthesis of film viewers: "through a focus on the physical activities of the actors, many new writings on screen performance inevitably conclude with what Ross Gibson calls 'a somatic response' on the part of the audience." ${ }^{30}$ Embodiment need not be theorized only as a spectatorial state that allows for affects and "somatic responses" as effects, but as a condition that enables these affects to participate in and co-produce the very meaning of the texts conceptualized as producing those effects. As such, it is the body's embodied apprehension of generic gestures that endows the gestures themselves as generically significant and signifying. As the body apprehends and is moved by the gestures of a genre, it produces the generic.

We might thus clarify that, more than recognize or respond, film viewers empathize, kinesthetically, with the gestures they see in genre films. I borrow Susan Foster's notion of kinesthetic empathy but extend it beyond the dance viewer whom she discusses. Susan Foster's compelling notion of kinesthetic empathy suggests that "perception simulates action ... The viewer, watching a dance, is literally dancing along." ${ }^{31}$ Due partially to the operation of mirror neurons, the body empathizes with the movements of those bodies it sees moving. Viewers, of all cinematic forms, thus dance along with film gestures; they enact genre in their moves. However, I would argue that this "dancing along" is also critical-a body can reject or revise these gestures and their accompanying ideologies in their own kinesthetic apprehension and articulation of them. Empathy need not be situated as a non-critical acceptance of movement. Brannigan expands upon Susan Foster's notion by looking to the work of John Martin. Martin posits that corporeal screen presence produces particular affects that include "the inherent contagion of bodily movement, which makes the onlooker feel sympathetically in his own musculature." 32 The kinesthetic empathy of viewers for the repeated gestures of genre films further reiterates and produces genre while linking genre production to the kinesthetic subjectivity of viewers. As such, the viewer's experience of their "own musculature" engages in the production of genre alongside other productive elements. As such, we might consider film genre as it is enacted by its gestures, as what dance scholar Janet Adshead-Lansdale calls a "dancing text," in which "the reader is not, then, a parasite upon a fixed object, sucking its life blood, but a co-creator of a mobile text, breathing new life into (it)." 33

Colloquial expressions referring to spectators' apprehension of films gesture towards the affective impact of such films. Film "move" and "touch" us; we claim to "take in a movie" (as in the expression "it was a lot to take in"). More than films just producing 
"somatic responses," they are taken in-possessed-by our bodies. Deleuze suggests this corporeal or kinesthetic incorporation of films with his theorizing of the movement-image in which:

There is inevitably a part of external movements that we 'absorb,' that we refract, and which does not transform itself into either objects of perception or acts of the subject; rather they mark the coincidence of the subject and the object in a pure quality. This is the final avatar of the movement-image: the affection image. ${ }^{34}$

While Deleuze's subject is not exclusively a spectator, the way in which he absorbs external movements that do not transfer themselves into actions or objects helps to articulate the way in which the spectator experiences generic gestures and participates in their genre. Brannigan articulates saliently the response of the spectator to the gesture in her analysis of dancefilm:

We are asked to provide for the occasion, or occurring of the actus, an unpremeditated, extemporaneous reaction that makes critical response a challenge. With nothing to hang onto but the potential of the gesture-as Lyotard describes it-we are left to our resources, compelled by these strange, summoning gestures to find a way to meet them. Beyond succumbing and indulging, we are put to work by the gestural dancefilm to produce an appropriate returning gesture. This is the impetus of such films: to produce, yield, bring out something exterior, yet akin to itself. We are called upon to improvise our response as we follow a trace of movements that we will never quite master, a choreography that will elude us each time despite the replay option. ${ }^{35}$

While Brannigan is addressing gestures within dancefilm, rather than genre films that include movement that might not be considered "dance" by many, the way in which she describes the viewer as being put to work to "produce an appropriate returning gesture," is akin to the response of the genre film viewer who also feels the "potential of the gesture" and is called upon to trace it and find a response. In this way, the genre film viewer is subjectified by the generic gesture and their body made a site in which genre plays out.

We carry genre with us, producing it in our bodies in their constant ability to reiterate and recall film gestures. Our muscles and skeletons carry traces of film genres and the potential of their gestures, and charge the very spaces in which we move. As Kathleen Stewart writes of affect, "the potential stored in ordinary things is a network of transfers and relays. Fleeting and amorphous, it lives as a residue or resonance in an emergent assemblage of disparate forms and realms of life." ${ }^{136}$ We might therefore look to locate genre in the residue-animate potential-its moves leave in the moving 
bodies of its spectators. ${ }^{37}$ It is here-in the moving and moved body-that screendance studies can best intervene in our theorizations of film genre.

\section{Biography}

Sarah Friedland is a filmmaker and choreographer working at the intersection of moving images and moving bodies. She received her BA in Modern Culture and Media from Brown University and studied under the mentorship and collaboration of dancefilm scholar Erin Brannigan at UNSW. She is currently in New York City working on a new dance film involving the textural manipulation of skin, fat and light.

Email: sarahmfriedland@gmail.com

Website: www.motionandpictures.com

\section{Notes}

${ }^{1}$ Erin Brannigan, Dancefilm, 7.

${ }^{2}$ My interdisciplinary approach to filmic movement models that established by Erin Brannigan, a dancefilm scholar whose work on dancefilm has been critical in the emergence of dancefilm studies.

${ }^{3}$ Adam Kendon, Gesture, 82.

${ }^{4}$ Rick Altman writes that "genre itself is typically thought of as a corpus of films." Film/Genre, 24.

${ }^{5}$ Barry Grant, Film Genre, 9.

${ }^{6}$ Grant, Film Genre Reader IX, xx.

${ }^{7}$ Altman, 84.

${ }^{8}$ Grant, Film Genre, 10.

${ }^{9}$ Idem., 34.

${ }^{10}$ Altman, 84.

11 Jacques Derrida, "The Law of Genre," 211.

${ }^{12}$ Steve Neale, Genre and Hollywood, 48.

${ }^{13}$ Roland Barthes, Mythologies, 114.

${ }^{14}$ Ibid.

${ }^{15}$ Idem., 117.

${ }^{16}$ Grant, Film Genre, 143. 
${ }^{17}$ Barthes, Mythologies in Ibid.

${ }^{18}$ Brian Massumi, Parables for the Virtual, 4.

${ }^{19}$ Barthes, 18.

20 Idem., 20.

21 "The gestural parameters of a given performer become a kind of performative domain that unifies a character, a film, and bodies of work. The gestural parameters, performative domain, or corporeal specificity of the dance start will be referred to as the performer's idiogest: their gestural idiolect." Brannigan, 142.

22 Idem., 172.

${ }^{23}$ Derrida, 204.

24 Idem., 41.

${ }^{25}$ Barthes, 130.

${ }^{26}$ Altman, 84.

${ }^{27}$ From Andrew Tudor, Theories of Film. Quoted in Neale, 18.

${ }^{28}$ See Vivian Sobchack, Carnal Thoughts, and Linda Williams, "Film Bodies."

${ }^{29}$ Sobchack, "What My Fingers Knew," original emphasis.

${ }^{30}$ Brannigan, 13.

31 Susan Foster, Choreographing Empathy, 123.

32 Brannigan, 12.

33 Janet Landsdale, Dancing Texts, 21.

${ }^{34}$ Gilles Deleuze, Cinema 1, 65.

${ }^{35}$ Brannigan, 178.

${ }^{36}$ Kathleen Stewart, Ordinary Affects, 21.

${ }^{37}$ It should be noted that my approach here, unlike my initial reference to Massumi, is inconsistent with his understanding of affect which "is unqualified... it is not ownable or recognizable, and is thus resistant to critique" (Massumi, "Autonomy of Affect," 88). I am, here, opening up affect to critique. However, my use of Stewart's "residue" is consistent with Massumi's notion of incipience, a term he substitutes for affect: "The body doesn't just absorb pulses or discrete stimulations; it infolds contexts, it infolds volitions and cognitions that are nothing if not situated. Intensity is asocial, but not presocial-it includes social elements, but mixes them with elements belonging to other levels of functioning, and combines them according to different logic. How could this be so? Only if the trace of past actions including a trace of their contexts were conserved in the brain and in the flesh, but out of mind and out of body understood as qualifiable interiorities, active and passive respectively, directive spirit and dumb matter. Only if past actions and contexts were conserved and repeated, autonomically reactivated, but not accomplished; begun, but not completed. Intensity is incipience, incipient action and expression. Intensity is not only incipience, but the incipience of mutually exclusive pathways of action and expression that are then reduced, inhibited, prevented from actualizing themselves completely-all but one. Since the crowd of pretenders to actualization are tending toward completion in a new context, their incipience cannot just be a conservation and reactivation. They are tendencies-in other words, pastnesses opening onto a future, but with no present to speak of... This 
requires a reworking of how we think about the body. Something that happens too quickly to have happened, actually, is virtual. The body is as immediately virtual as it is actual. The virtual, the pressing crowd of incipiencies and tendencies, is a realm of potential." Massumi, "Autonomy of Affect," 223-224.

\section{References}

Adshead-Lansdale, Janet. Dancing Texts: Intertextuality in Interpretation. London: Dance Books, 1999.

Altman, Rick. Film/Genre. London: British Film Institute, 1999.

Barthes, Roland. Mythologies. New York: Macmillan, 1972.

Brannigan, Erin. Dancefilm: Choreography and the Moving Image. Oxford: Oxford University Press, 2011. http://dx.doi.org/10.1093/acprof:oso/9780195367232.001.0001

Deleuze, Gilles. Cinema 1: The Movement Image. Translated by Hugh Tomlinson and Barbara Habberjam. Minneapolis: University of Minnesota Press, 1986.

Derrida, Jacques, and Avital Ronell. "The Law of Genre." Critical Inquiry (1980): 55-81. http://dx.doi.org/10.1086/448088

Foster, Susan Leigh. Choreographing Empathy: Kinesthesia in Performance. New York: Routledge, 2010.

Grant, Barry Keith. Film Genre Reader IV. University of Texas Press, 2012. . Film Genre: From Iconography to Ideology. London: Wallflower Press, 2007.

Kendon, Adam. Gesture: Visible Action as Utterance. Cambridge: Cambridge University Press, 2004. http://dx.doi.org/10.1017/CBO9780511807572

Lyotard, Jean-François. "Gesture and Commentary." Translated by Stephen Adam Schwartz. Iyyun, The Jerusalem Philosophical Quarterly 42 (1993): 37-48.

Massumi, Brian. "The Autonomy of Affect." Cultural Critique (1995): 83-83. http://dx.doi.org/10.2307/1354446

Massumi, Brian. Parables for the Virtual: Movement, Affect, Sensation. Durham: Duke University Press, 2002. http://dx.doi.org/10.1215/9780822383574 
Neale, Steve. Genre and Hollywood. London: Routledge, 2000.

Sobchack, Vivian. "What My Fingers Knew, The Cinesthetic Subject, or Vision in the Flesh." Senses of Cinema 5 (2000). http://sensesofcinema.com/2000/conferencespecial-effects-special-affects/fingers/

. Carnal Thoughts: Embodiment and Moving Image Culture. Berkeley: University of California Press, 2004.

Stewart, Kathleen. Ordinary Affects. Durham: Duke University Press, 2007. http://dx.doi.org/10.1215/9780822390404

Tudor, Andrew. Theories of Film. London, Secker and Warburg, 1974.

Williams, Linda. "Film Bodies: Gender, Genre, and Excess." Film Quarterly 44.4 (1991): 213. http://dx.doi.org/10.2307/1212758 